\title{
Segmentation analysis of financial savings markets through the lens of psycho-demographics
}

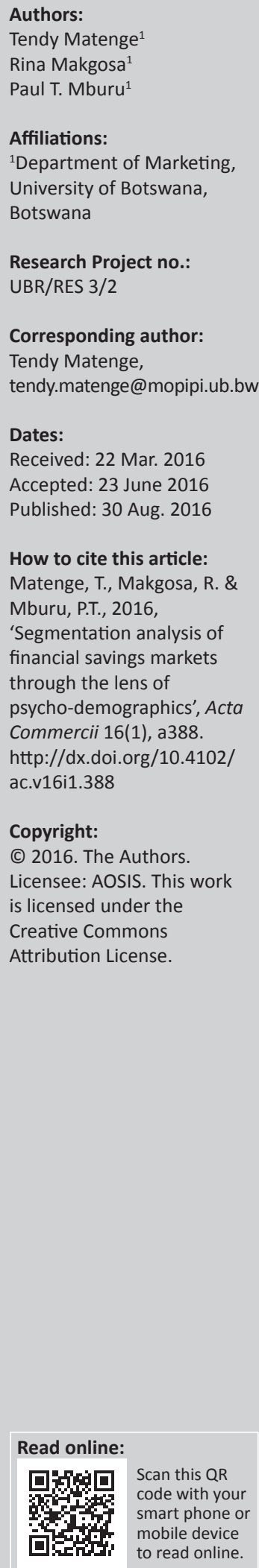

Purpose: This study seeks to contribute to the discourse of financial savings market segmentation. The study explores different segments of savers on the basis of demographic and psychographic characteristics that are unique to each segment relying on the perspectives of a sample of consumers of financial saving programmes.

Design/methodology/approach: Principles of perceptual mapping were used to analyse 33 semi-structured interviews that gathered data on the participants' psychographic make-up such as personal values, motives for saving, attitudes towards savings and perceived conditions of savings.

Findings: Eight distinct segments emerged on each psychographic characteristic based on the participants' demographics of income, gender and age. However, only five were sizeable enough to be interpreted, being three segments from the males' category and two from the females' category. The three segments that emerged within the male category are young lowincome earners (YoLI), young high-income earners (YoHI) and old high-income earners (OHI) while the two female segments include YoLI and OHI. The most sizeable segment of savers in both gender-based categories is one of old adults who have a high income. These segments vary in terms of values, motives and perceptions.

Originality/value: The study suggests that a multi-dimensional approach of segmenting financial savings markets is more effective, as neither the demographic nor the psychographic segmentation can fully describe the saving behaviour of consumers.

Research implications: The findings of the present study provide strategic communication implications for financial institutions for the respective segments.

\section{Introduction}

Market segmentation is fundamental to the understanding of financial savings markets as it allows marketers of saving programmes to identify homogeneous subsets of savers based on relevant characteristics, needs and behaviours as well as the corresponding marketing mix (Keller \& Siegrist 2006; Meadows \& Dibb 1998; Minhas \& Jacobs 1996). Beyond the benefits relating to the identification of segments of savers and effective targeting and positioning by the financial institutions, segmentation based on saving behaviour also leads to improved resource allocation, identification of market opportunities, improved competitive advantage and profitability (Kotler $\&$ Keller 2008). From the customers' perspective, segmentation enables them to obtain financial services that are aligned with their value requirements, which translates into increased overall satisfaction.

A great deal of empirical research has acknowledged several dimensions that are useful when segmenting markets for personal financial services such as demographics (Javalgi \& Dion 1999), psychographics (Foscht et al. 2010; Harrison 1994; Muhamad, Melewar \& Alwi 2012) and benefits (Alfansi \& Sargeant 2000; McDougall \& Levesque 1994; Minhas \& Jacobs 1996). Although the segmentation of financial savings markets is not new, research that utilises a multi-dimensional approach is negligible. Specifically, the segmentation of financial services mostly places emphasis on demographic segmentation or psychographic segmentation. However, previous research has stressed that the utilisation of a multi-dimensional approach to segmentation is imperative to fully understand the consumer behaviour on financial products (Harrison 1994; Loibl \& Scharff 2010; Piercy, Campbell \& Heinrich 2012). The approach has the potential to generate a profound effect on marketing strategies for building relationships with particular market segments (Ansell, Harrison \& Archibald 2007). As such, some scholars have attempted to examine segments of financial services using combinations of demographics and lifestyles (Ansell et al. 2007), 
demographics and attitudes (Keller \& Siegrist 2006) as well as demographics and benefits (Minhas \& Jacobs 1996).

\section{Problem statement}

While the rate of borrowing is on the rise, the rate of consumer savings has decreased significantly in most societies (Devaney, Anong \& Whirl 2007; Yuh \& Hanna 2010). For instance, the rate of personal savings has been reported to have declined drastically during the past decade for the vast majority of the British population (Burton 2001), American households (Devaney et al. 2007; Fisher \& Anong 2012) and people in Botswana (Modisaatsone 2013). The declining level of personal savings in relation to debt poses a challenge to individuals, financial systems and economies. When a majority of people in the society do not save at an early age, they will not be in a position to satisfy their consumption needs in the future, which is more likely to increase overdependence on government at their retirement age (Burton 2001). A low level of household savings also has a great potential to negatively affect the process of accumulating resources that can be utilised for investment purposes by the financial systems, which in turn diminishes capital stock in the economies (Elbadawi \& Schmidt-Hebbel 1998; Haruna 2011; Prinsloo 2000; Radipotsane 2006).

\section{Study objectives}

Given that a combination of bases of segmentation helps to describe and explain patterns of behaviour of consumers of financial services, the primary purpose of the present study is to contribute to the understanding of the market for financial services and savings in particular. The specific objective is to explore possible different segments of consumers of financial saving programmes on the basis of demographic and psychographic characteristics that are unique to each segment.

\section{Literature review}

\section{Segmentation of financial services markets}

Market segmentation is widely recognised as an integral part of strategic marketing (Doyle 1987; Harrison 1994; Minhas \& Jacobs, 1996). It is a three-step process that entails identifying the market, selecting one or more sub-segments to serve and directing the marketing mix to each specific segment (Fahy \& Jobber 2012). In the context of financial services marketing, it offers financial institutions the opportunity to divide the market into subsets of consumers based on similar needs and characteristics and identifying which segment(s) to serve with the firm's marketing effort (Kotler \& Keller 2008; Muhamad et al. 2012).

The understanding of the market for personal financial services is critical for financial service providers. Personal financial services are diverse (Minhas \& Jacobs 1996) and may comprise bank savings, building society savings plans, pension schemes, insurance policies, mortgage bonds, real estate securities, shares, personal loans, and home loans. The types of personal financial services also vary according to the interest rate they attract, risk involved and rates of return (Meier, Kirchler, \& Hubert 1999). Additionally, the purchase of personal financial services is quite complex for consumers to comprehend as decisions are not once-off in nature but rather tend to continue for many years (Burton 2001).

The market for financial services has also undergone tremendous transformations since the 1990s. According to Harrison (1994), the market for financial services in Britain, for example, was characterised by increased product proliferation and the importance of marketing in ensuring expansion and diversification before the 1980s. However, the deregulation of the financial market that occurred in the 1990s has significantly reduced legal restrictions allowing the rivalry among financial providers to intensify. The structural changes in the market for personal financial services are observable in factors such as increased competition, market saturation, recession, reduced demand for financial services, rising operational costs and diminishing profit margins (Ansell et al. 2007; Harrison 1994). The major drivers for these changes have been the deregulation of the market for financial services, technological advancements and changes in socioeconomic conditions (Javalgi \& Dion 1999; Meadows \& Dibb 1998; Minhas \& Jacobs 1996).

Structural changes occurring in the personal financial market have fundamental implications for financial consumer behaviour. In particular, while the rate of borrowing is on the rise, the rate of consumer savings has decreased significantly in most societies (Devaney et al. 2007; Yuh \& Hanna 2010). For instance, the rate of personal savings has been reported to have declined drastically during the past decade for the vast majority of the British population (Burton 2001), American households (Devaney et al. 2007) and people in Botswana (Modisaatsone 2013). The declining level of personal savings in relation to debt poses a challenge to individuals, the financial system and the economy. When a majority of people in the society do not save at an early age, they will not be in a position to satisfy their consumption needs in the future, which is more likely to increase over-dependence on government at their retirement age (Burton 2001). A low level of household savings also has a great potential to negatively affect the process of accumulating resources that can be utilised for investment purposes in the financial system, which in turn diminishes capital stock in the economy (Elbadawi \& Schmidt-Hebbel 1998; Haruna 2011; Prinsloo 2000; Radipotsane 2006). Thus, the importance of understanding consumers of financial services is long overdue, and the need to develop relevant market segmentation strategies concentrating on the needs of homogeneous groups within a larger, diverse financial market is on the rise (Coffey \& Palm 1999; Harrison 1994; Loibl \& Scharff 2010; Yuh \& Hanna 2010). Furthermore, effective segmentation of the financial market leads to improved resource allocation, better identification of market opportunities and the development of superior marketing strategies (Kotler \& Keller 2008). 
Previous studies of segmentation place emphasis on two approaches: a priori and post hoc approach (Muhamad et al. 2012). In the a priori approach, the researcher selects a basis for segmentation and then uses common sense in classifying consumers into segments mostly relying on demographic characteristics. The post hoc approach divides the market into segments based on the extent to which responses obtained from the survey on specific characteristics are similar using sophisticated quantitative analytical techniques such as cluster analysis, perceptual mapping and discriminant analysis. The available studies based on the post hoc approach tend to segment the financial services market based on different combinations of demographic variables and psychographic characteristics (Ansell et al. 2007; Keller \& Siegrist 2006; Minhas \& Jacobs 1996) or demographic characteristics and desired benefits (Alfansi \& Sargeant 2000). Other scholars have utilised factors that attempt to explain the psychographic nature of the customers such as perceptions (Harrison 1994), attitudes (Foscht et al. 2010; Fünfgeld \& Wang 2009) and motivations (Muhamad et al. 2012) or grouped consumers based on their expected benefits from consuming the product such as desired utility, overall customer satisfaction and perceived value (Alfansi \& Sargeant 2000; McDougall \& Levesque 2000).

It is apparent from the review of the literature that the topic of segmentation of financial services has attracted considerable academic attention in both developing (Alfansi \& Sargeant 2000; Muhamad et al. 2012) and developed countries (Ansell et al. 2007; Strandberg, Wahlberg \& Óhman 2012). Although research into the strategic importance and approaches of market segmentation for personal financial services is well established in developed countries, the same cannot be said about developing countries (Alfansi \& Sargeant 2000). As more and more studies are conducted on the various bases of market segmentation in the personal financial market in different contexts, the most effective bases that reflect the unique realities of those contexts tend to emerge.

\section{Demographic segmentation}

Demographic variables of age (Burton 2001), income, profession (Friedman 1957), stage in the family life cycle (Albert \& Modigliani 1963; Javalgi \& Dion 1999) and social class have been widely used as the most traditional basis for segmenting the market for personal financial services. The use of demographics for segmentation in the context of understanding consumers of financial services corresponds with the life cycle model and the permanent income hypotheses. The life cycle model proposed by Albert and Modigliani (1963) contends that consumption and saving reflect an individual stage in the life cycle, while the permanent income hypotheses of Friedman (1957) are based on the premise that consumption is determined by long-term income. For instance, studies on age-based segmentation of market for financial services have shown that young people will save less while older people will save more (Albert \& Modigliani 1963; Burton 2001; Javalgi \& Dion 1999). Studies based on the family life cycle concept have demonstrated that the rating of attributes considered important when choosing financial institutions and the importance of financial services offered by financial institutions differ across the stages of the life cycle (Albert \& Modigliani 1963; Javalgi \& Dion 1999). In particular, individuals in the bachelor stage rated attributes such as located near home, overall quality of service, reputation and ease of qualifying for free cheque accounts by maintaining a minimum balance to be critical in making a decision to choose a financial institution; while those in the full-nest 1 stage rated attributes such as location, reputation, availability of mortgage loans, low interest rates on loans and giving good financial advice as very important.

Although traditional demographic characteristics can be useful in describing the financial market, it appears they are being heavily criticised within the literature (Foscht et al. 2010; Harrison 1994). Such bases have been criticised for providing little insight into the behaviour of the consumers of financial services as they are overly simplistic or descriptive (Harrison 1994). It has been argued that demographic characteristics can easily become inferior as a result of societal changes such as family structures or any changes in trends relating to social structures (Piercy et al. 2012) possibly leading to a mismatch between customers and financial offerings (Machauer \& Morgner 2001). Additionally, demographic characteristics do not fully explore the potential of segmenting the market for financial services as most previous studies have used only one demographic variable at a time and results based on these studies are incapable of identifying the complete characteristics of sub-markets (Javalgi \& Dion, 1999; Kotler \& Armstrong 1999).

\section{Psychographic segmentation}

A major stream of research on the segmentation of consumers in the financial markets concentrates on psychographic characteristics such as personality, motivation, knowledge, attitudes, perceptions, lifestyles and values (Aaker 1997; Feng Lin 2002; Kotler et al. 2009; Muhamad et al. 2012). The premise of this approach of segmenting financial markets is the idea that there is heterogeneity that exists in terms of psychographic characteristics within a seemingly 'homogenous' group based on demographics and thus each segment would require a different mix of strategies to satisfy the individual needs of consumers (Feng Lin 2002; Muhamad et al. 2012). Consumers have been found to exhibit different motives, personalities, personal values and lifestyles even in the same demographic category (Kotler et al. 2009). Specifically, consumer personalities, values and lifestyles are indeed important indicators of product association because when consumers make a decision about a product, they also make an association of the product image with their own personality or image (Aaker 1997).

During the early stages of psychographic segmentation in financial services, Harrison (1994) identified four segments based on their perceptions about their knowledge of financial services and their degree of financial maturity. The identified 
segments were the financially confused, the apathetic minimalist, the cautious investor and the capital accumulators. The financially confused were characterised by low levels of perceived knowledge and financial maturity, future orientations for savings and short-term investment. On the other hand, the apathetic minimalists are financially mature, although their perceived knowledge of financial services is low, which then affected their motivation to use these services. The cautious investors perceived themselves to be financially knowledgeable, yet they displayed moderate levels of financial maturity by opting to use complex yet 'safer' saving options like insurance and pension funds and thereby having a long-term orientation to savings. The capital accumulators segment is characterised by high perceived levels of financial knowledge and financial maturity; thus, this segment was found to use savings options considered to be highly risky such as speculative share investments and low-rated bonds. Expanding on the earlier works, Foscht et al. (2010) identified four segments of consumers of financial services based on their level of interest, usage patterns, loyalty and behavioural intentions. Cluster 1 was found to be young people who are mainly interested in conservative forms of investments such as savings accounts and home loans, while cluster 2 had a relatively high interest in debit/ credit cards and high-risk forms of investments. As in cluster 1, cluster 3 was found to be inclined towards more conservative forms of investments such as savings accounts despite their older age while cluster 4 showed more interest in high-risk forms of investment.

In a previous study, consumers of financial services related to Islamic banking were grouped into four segments, namely religious convictions, ethical observers, economic rational and a combination of economic and religious conviction based on their motives to buy these products (Muhamad et al. 2012). The religious conviction segment is highly motivated by the need to adhere to religious values in making decisions, the ethical observant segment consists of those who seek to ensure that their actions are morally acceptable and the economic rational segment make decisions based on personal benefits. Using attitudes towards financial matters, segments from a previous study were labelled as rational consumers, myopic consumers, anxious consumers, gut feeling consumers and anxious spenders (Fünfgeld \& Wang 2009). The rational consumers are highly concerned with economic and financial matters. Myopic consumers are secure and not anxious when it comes to financial matters. Anxious savers need precautionary saving while anxious spenders feel insecure about financial matters. Gut feeling followers are spontaneous and trust their intuition in their financial decision making.

Despite the insight from the literature that discussed psychological segmentation in personal financial markets, the issue of personal saving has been rarely studied. With the exception of the study by Foscht et al. (2010), the key limitation of the previous studies is that they tend to focus on a single psychographic variable or a limited set of psychological variables in one study at a time. Thus, this approach does not provide adequate valuable insight into the understanding of the psychographic make-up of savers.

\section{Benefit segmentation}

This approach segments customers according to benefits they seek when purchasing financial services, which is directly related to future purchase behaviour (Minhas \& Jacobs 1996). Although the approach of segmenting consumers in the financial markets according to their desired benefits has attracted relatively limited attention from past studies, it is gradually recognised as an effective method for understanding consumers of financial services. Minhas and Jacobs (1996) also highlighted the need for segmenting the market looking at the benefits sought because it closes the knowledge gaps left by studies that focus on the demographic and psychographic segmentations. In particular, McDougall and Levesque (1994) identified two segments based on consumers' desire for benefits being the performance and convenience segments. The performance segment describes consumers who desire the services of the bank to be performed right the first time, whereas the convenience segment identifies consumers who seek convenience in banking services such as convenient opening hours and accessible branch locations. In addition, three segments labelled as relationships, costsensitive and service focussed were identified on the basis of benefit variables sought in a bank (Alfansi \& Sargeant 2000). The relationships focussed on segment placed more emphasis on the security of a banking relationship and were more likely to select a bank based on knowledge of the bank's employees or the recommendation of a close friend. Cost-sensitive consumers are highly interested in promotional incentives, banking technology and convenience. Service-focussed consumers attach a high level of importance to core services such as bank reputation, the speed of delivery, accuracy of transactions as well as augmented services such as the quality of interaction with the staff.

Although studies on benefit segmentation offer valuable information on what savers look for within a bank, there is a need for some form of consistency concerning the range of benefits sought. The concern is that each study applies different types of benefits sought, yielding varied typologies of consumers of banking services and it remains unclear which are the most widespread benefits-based segments. This approach also does not adequately capture other important questions that are necessary to understand consumers of saving programmes such as who saves, why they save and whether saving is an important value among individuals. Such questions are usually addressed through psychological variables such as personality, motivation and personal values. Therefore, a more combined segmentation approach is required.

\section{Multi-dimensional segmentation}

As shown in the reviewed literature, a considerable proportion of past studies relating to segmentation of 
financial markets have relied on one-dimensional bases of segmentation. As each base of segmentation has notable strengths and limitations, it therefore increasingly becomes logical for marketers to use the multi-dimensional approach that combines the various bases for segmentation in order to take advantage of the benefits that are associated with each base. The fundamental advantage of this approach is that it attempts to address and avoid weaknesses of relying on a single base of segmentation by combining different factors, which is critical in the development of effective marketing strategies (Harrison 1994; Piercy et al. 2012), and it increases the opportunities of ensuring the quality of market segmentation (Loibl \& Scharff 2010; Wind 1978).

Relatively, limited studies relating to segmentation of financial markets have adopted the multi-dimensional segmentation relying on a combination of segmentation bases such as demographics and benefits, demographics and attitudes as well as demographics and financial sophistication. For example, a set of eight benefits were found to vary among different groups of consumers of financial services based on demographics such as occupation, education, gender and age (Minhas \& Jacobs 1996). Benefits such as unlimited banking, accessible cash and advice were more appealing to young people who were either unemployed or occupy lowstatus jobs; and personal service was more attractive for those with fewer skills and education. Money management was a core benefit for those in the middle-age group with limited resources. Young, well-educated professionals, especially male professionals, were keen on full-service banking while investments were important for pensioners. Four segments emerged based on money attitudes and demographics, which were labelled as safe players, open books, money dummies and risk seekers (Keller \& Siegrist 2006). The safe players are older than 65 and have positive attitudes towards personal financial security and saving. Safe players plan most financial matters carefully, keep proper records of their spending and perceive saving money as more important than spending. Open books are middle-aged and highly educated individuals who have low confidence and interest in financial matters, yet they tend to be keen to discuss their personal financial situations with others. Money dummies have attained vocational training and exhibited the lowest level of interest in stock markets, savings and financial security. Risk seekers have the highest levels of education, income, attitudes towards stock markets and are confident in handling money, but find financial security and saving money to be of less importance. Additionally, consumers of financial services were segmented on the basis of age and level of financial sophistication (Ansell et al. 2007). This yielded six segments labelled financially involved adults, moderately financially active adults, sophisticated early starters, financially moderate seniors, sophisticated middle agers and sophisticated late starters. These segments explained how the level of involvement with their personal finances differed among age groups.

The multi-dimensional approach of segmentation becomes critically important to academics and financial institutions as they seek to adopt more meaningful and reliable means of understanding personal financial markets. Therefore, in order to extend knowledge about market segmentation in the financial markets, a multi-dimensional segmentation approach has been adopted in this study. Specifically, the present study focusses on three demographic characteristics, namely, gender, age and income, and four psychographic characteristics, namely, personal values, attitudes, motives and perceived conditions of saving. Personal values represent enduring beliefs about the desirability of particular end states of existence (Kahle 1983). Attitudes are a function of beliefs and evaluations derived from feelings about consequences of a particular behaviour (Loibl \& Scharff 2010). Motives are drives that compel people to act such as needs and desires (Devaney et al. 2007). Perceived conditions of savings related to people interpret problems associated with savings in the lens of market environment.

The present study offers a more comprehensive integration and a mix of variables from two segmentation bases usually applied (namely, demographic and psychographic). A consolidation of multiple variables is a justifiable attempt with important implications for research avenues such as who saves, why they save, how do attitudes predict saving behaviour, what conditions are associated with saving and is saving an important part of one's life. Attitudes for saving money, saving motives and perceptions of financial knowledge have been studied as segmentation bases in personal financial markets in a single study at a time. However, personal values (also linked to psychographic variables) together with selected demographics have been rarely applied in studies of financial services and savers in particular and not considered in the context of Botswana.

\section{Methodology}

This study adopts a qualitative research design, which is grounded in the interpretivist perspective (Carson et al. 2001). This perspective is useful in gauging the respondents' meaning, experiences and interpretations in order to have a more comprehensive understanding of their saving behaviour, which is consistent with the study by Muhamad et al. (2012). The target population of the present study was employed citizens adults aged between 18 and 64 years, resending in Gaborone Botswana.

The participants of the qualitative study were 33 employed adult citizens aged between 18 and 64 years. The participants were screened using two questions. The first qualification criterion was whether the respondent is employed and aged between 18 and 64 years. Employed adults were targeted rather than employed children (17 years or less), as the employment of children is prohibited by the Botswana Employment Act. The second qualification criterion was whether the respondent has set aside cash earnings as savings. Employed adults who receive cash earnings in Botswana constitute $73 \%$ of the total labour force (Central Statistics Office 2008). The participants were recruited using 
purposive sampling and volunteered to be interviewed for the purposes of this study from their places of work.

Out of a total of 43 employed adults who were interviewed, 33 confirmed to be savers. The sample size was considered adequate for providing insight into segments of savers. The review of the literature of consumer research associated with financial market segmentation has demonstrated that a minimum of 10 and a maximum of 30 interviews could be used (see, Harrison 1994; Muhamad et al. 2012). Semistructured interviews by way of an interview guide were used to collect data. The interview guide contained openended questions associated with four psychographic variables such as personal values, motives, attitudes and perceptions of conditions of saving. Selected demographic characteristics such as gender, age, income, education, occupation, marital status and a number of children were also included (see Appendix 1, Table 1-A1). Two researchers collected data through semi-structured interviews during working days for a period of 3 weeks, averaging one interview per researcher per day. Audiotapes were used to ensure that all the experiences and impressions of savers were captured, which increased the trustworthiness of the qualitative methodology.

All audiotaped interviews were transcribed and typed to facilitate data analysis. Each research read through the transcript and coded the responses. Then, researchers compared their individual results of the themes for each question and discussed the discrepancies until a consensus was reached. Data were analysed using the principles of perceptual mapping. Generally, perceptual mapping is used to depict the positioning of competing products (Young 1999). The technique provides opportunities for identifying potential returns and problems associated with the marketing mix (Minhas \& Jacobs 1996; Young 1999). The concept of perceptual mapping is used in this qualitative study in order to identify the specific characteristics that are associated with specific sub-segments of savers grouped according to demographic and psychographic characteristics. Data analysis proceeded in three stages: In the first stage, themes were identified and categorised according to existing theories. In the second stage, savers were grouped into subsegments based on gender, age and income. Lastly, specific psychological characteristics associated with savers in each demographically identified segment were identified using the concept of perceptual mapping.

\section{Ethical considerations}

This research has been approved by the University of Botswana ethics committee and a research permit was granted by the Ministry of Finance and Development Planning, reference number FDPC 71/6/25/Vol.22.

\section{Findings}

\section{The demographic profile of the sample}

Out of the 33 participants who were interviewed, 55\% were male while $45 \%$ were female participants as presented in Table 1. A higher proportion of male in relation to female participants correspond to the general gender and labour statistics in Botswana (Central Statistics Office 2008). A majority of respondents within the male segment falls in the age category less than 30 years (39\%), which is followed by those in the age group 30-39 years constituting 28\% and in the age group 40-49 years constituting 22\%. The male category is highly educated having attained either a bachelors (22\%) or graduate degree $(33 \%)$. The common income bracket for the male category is P15 000-P19 999 (22\%). More than half of the male category is made up of those who are married (56\%), have fewer than two children $(20 \%)$ and are either employed or self-employed managers or work as professionals $(44 \%)$. Within the female category, most participants were aged between 30 and 39 years (47\%), followed by those less than 30 years (27\%), with $33 \%$ having

TABLE 1: Demographic characteristics of male and female savers.

\begin{tabular}{|c|c|c|}
\hline \multirow[t]{2}{*}{ Variables } & \multicolumn{2}{|c|}{ Gender } \\
\hline & Males & Females \\
\hline \multicolumn{3}{|l|}{ Age } \\
\hline Less than 30 years & $7(39 \%)$ & $4(27 \%)$ \\
\hline $30-39$ years & $5(28 \%)$ & $7(47 \%)$ \\
\hline $40-49$ years & $4(22 \%)$ & $2(13 \%)$ \\
\hline 50-59 years & $2(11 \%)$ & $2(13 \%)$ \\
\hline Total & $18(100 \%)$ & $15(100 \%)$ \\
\hline \multicolumn{3}{|l|}{ Education } \\
\hline Senior School Certificate & $1(6 \%)$ & - \\
\hline Diploma or Equivalent & - & $5(33 \%)$ \\
\hline Bachelor's & $4(22 \%)$ & $3(20 \%)$ \\
\hline Graduate (MBA and above) & $6(33 \%)$ & $3(20 \%)$ \\
\hline Some Tertiary Certificate & $7(39 \%)$ & $4(27 \%)$ \\
\hline Total & $18(100 \%)$ & $15(100 \%)$ \\
\hline \multicolumn{3}{|l|}{ Income } \\
\hline Less than P5000 & $2(11 \%)$ & - \\
\hline P5000-P5999 & $3(17 \%)$ & $6(40 \%)$ \\
\hline P10 000-P14 999 & $3(17 \%)$ & $3(20 \%)$ \\
\hline P15 000-P19 999 & $4(22 \%)$ & $4(27 \%)$ \\
\hline P20 000-P24 999 & $1(6 \%)$ & - \\
\hline P25 000-P29 999 & $3(17 \%)$ & $1(7 \%)$ \\
\hline P30 000 and more & $1(6 \%)$ & $1(7 \%)$ \\
\hline Did not disclose & $1(6 \%)$ & - \\
\hline Total & $18(100 \%)$ & $15(100 \%)$ \\
\hline \multicolumn{3}{|l|}{ Marital status } \\
\hline Single & $5(28 \%)$ & $9(60 \%)$ \\
\hline Divorced & $1(6 \%)$ & $1(7 \%)$ \\
\hline Cohabiting & $2(11 \%)$ & $1(7 \%)$ \\
\hline Married & $10(56 \%)$ & $4(27 \%)$ \\
\hline Total & $18(100 \%)$ & $15(100 \%)$ \\
\hline \multicolumn{3}{|l|}{ Occupational status } \\
\hline Full-time senior manager & $7(39 \%)$ & $7(47 \%)$ \\
\hline Full-time middle manager & $3(17 \%)$ & - \\
\hline Full-time junior manager & $1(6 \%)$ & $2(13)$ \\
\hline Professionals (Lecturers and Accountants) & $8(44 \%)$ & $5(33)$ \\
\hline Secretary & $1(6 \%)$ & $1(7 \%)$ \\
\hline Total & $18(100 \%)$ & $15(100 \%)$ \\
\hline \multicolumn{3}{|l|}{ Number of children } \\
\hline 0 & $6(33 \%)$ & $1(7 \%)$ \\
\hline $1-2$ & $9(50 \%)$ & $10(67 \%)$ \\
\hline $3-4$ & $3(17 \%)$ & $3(20 \%)$ \\
\hline More than 4 & - & $1(7 \%)$ \\
\hline Total & $18(100 \%)$ & $15(100 \%)$ \\
\hline
\end{tabular}

Source: Authors' own work 
attained a diploma. The female category had a predominant representation of singles $(60 \%)$, whose earnings range between P5000 and P9999 (40\%). Most female participants were employed as professionals and managers (47\%) and have two or fewer children $(67 \%)$. For a more qualitative perspective of the characteristics of participants, see Appendixes 1 and 2.

\section{Segments of savers based on psycho-demographics}

The results relating to the personal values of male and female savers identified eight segments. Figure 1 shows that in the male category, there is a segment of young low-income earners (YoLI male segment). The YoLI male participants seemed to be saving in order to meet their personal values of satisfying basic necessities, having fun and generally enjoying life with some sense of belonging (family, religion, spirituality and caring for children). They mostly saved because they value the prospect of security and safety (own house, education, saving money, peace, retirement plans, the future), coupled with a sense of self-fulfilment (having a nice car, expensive clothes, assets accumulation, more money). Another segment of young high-income earners (YoHI male segment) place most emphasis on security and safety as well as a sense of accomplishment (career, farming, own business, health, personal freedom). To a lesser extent, the YoHI male segment also values satisfying basic necessities. The third segment of older low-income earners (OLI male segment) value satisfying basic necessities, security and safety and a sense of belonging. The fourth segment consists of older high-income earners (OHI male segment) who value security and safety (property ownership, saving money, education and good health) and a sense of belonging (family, children and education). To a lesser extent, the OHI male segment values self-fulfilment, a sense of accomplishment, as well as having fun and generally enjoying life. The most prominent values in the male category are security and safety (YoLI male, YoHI male and OHI male segments), selffulfilment (YoLI male segment) and a sense of belonging (OHI male segment).

Similarly, four segments emerged in the female category. In this category, younger low-income earners (YoLI female segment) mostly value a sense of belonging, while security and safety is valued to a lesser extent. Another segment of younger highincome earners (YoHI female segment) was found to mostly

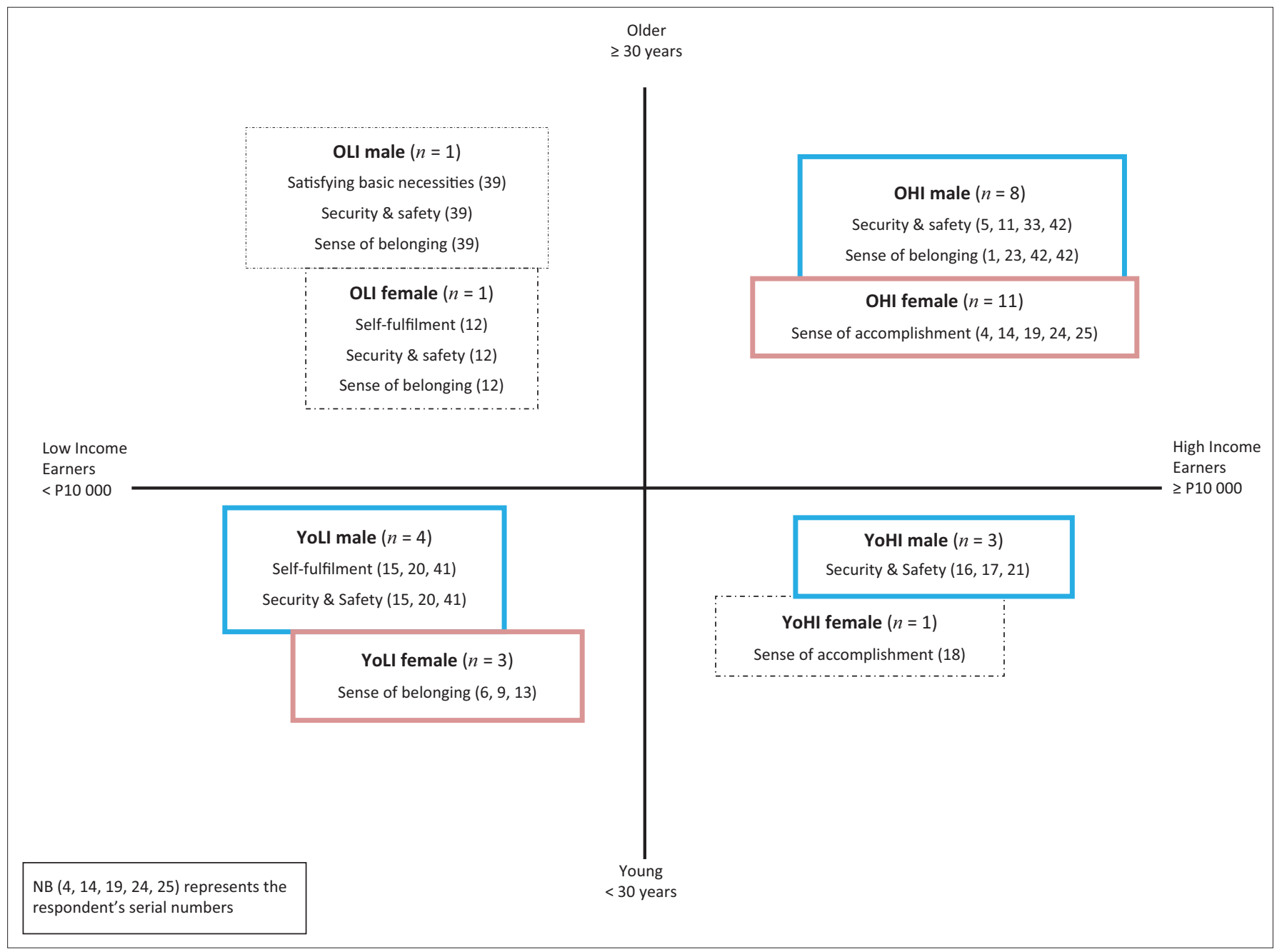

Source: Authors' own work

FIGURE 1: Personal values of savers. 


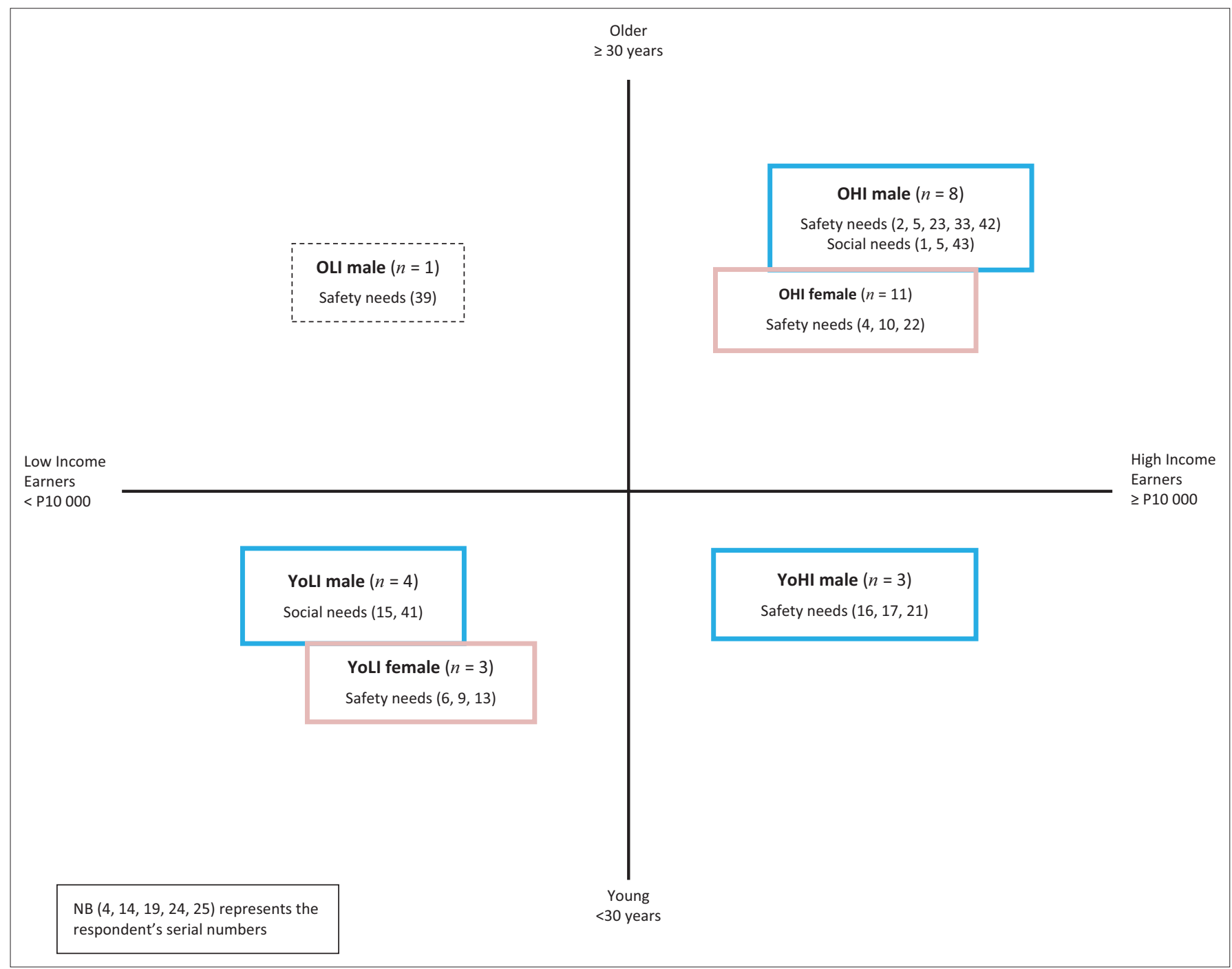

Source: Authors' own work

FIGURE 2: Motives for saving.

value a sense of accomplishment. On the other hand, the older high-income earners (OHI female) segment mostly values a sense of accomplishment. To a lesser degree, the $\mathrm{OHI}$ female segment values a sense of belonging, self-fulfilment, and safety and security. The fourth segment of old low-income earners (OLI female segment) values safety and security, a sense of belonging and self-fulfilment. The most prominent values in the female category are a sense of accomplishment (OHI female segment) and a sense of belonging (YoLI female segment).

Overall, segments that are sizeable and stand out based on a combination of personal values, age, gender and income are the $\mathrm{OHI}$ male, OHI female, YoLI male, YoLI female and YoHI male segments. The OLI male, OLI female and YoHI female segments are poorly represented and are therefore small segments.

Six segments emerged on motives for saving. Four of these segments are in the male category. The results in Figure 2 reflect that in the male category, YoLI male segment seems to be motivated to save primarily by social needs. Accompanying needs of lesser motivation are safety needs (retirement, medical expenses, emergencies, unforeseen circumstances), self-esteem (education, personal goal, entertainment) and self-actualisation (own a firm, opportunity exploitation). The only motivation factor that drives the YoHI male segment to save is safety, and while this is also the only driving motivation factor for the OLI male segment, it is less emphasised in the latter segment. Lastly, the $\mathrm{OHI}$ male segment is motivated to save mostly by safety needs and social needs. While selfesteem and self-actualisation are also motivating factors for this segment, their importance is less emphasised.

In the female category, only two segments emerged, being the YoLI female and OHI female groups. The YoLI female segment is primarily motivated to save by safety needs. Social needs (children, education, future and family) and self-esteem needs are also motivational factors but to a lesser degree. In the $\mathrm{OHI}$ female segment, safety needs emerged as the key motivating factor with self-actualisation being less influential.

Overall, the segments that stand out and are sizeable based on the combination of motives for savings, age, gender and income are $\mathrm{OHI}$ male, YoLI male, YoHI male, $\mathrm{OHI}$ female and 


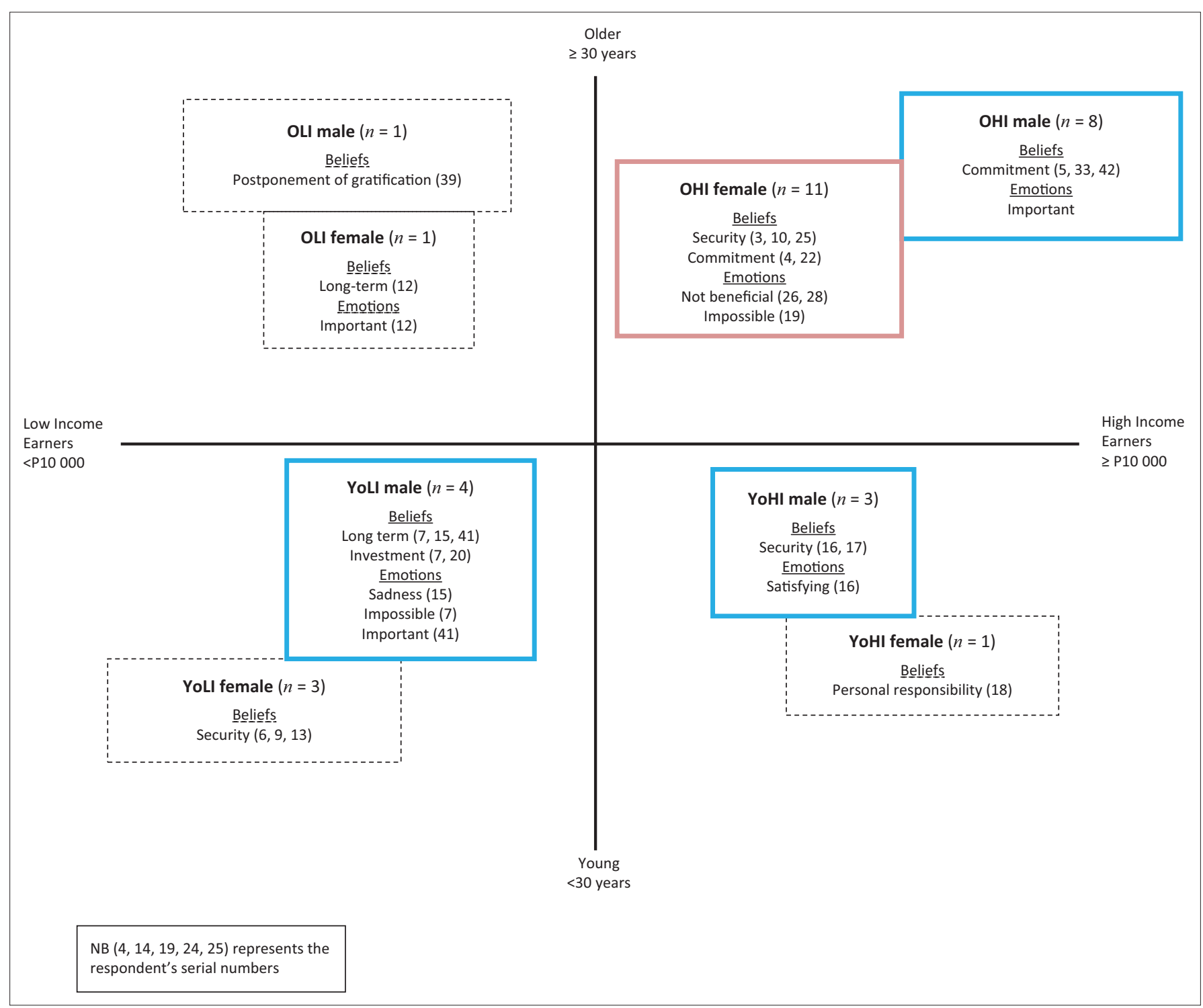

Source: Authors' own work

FIGURE 3: Attitudes of savers.

YoLI female segments. The OLI male segment is poorly represented.

In Figure 3, eight segments are identified based on the attitudes of savers. The YoLI male segment mostly believes that saving is a long-term investment. Even though it is to a lesser degree, they also believe that saving is a postponement of gratification that should be driven by some purpose and is to be cultivated at a young age. This segment further expressed mixed emotions about saving, showing that it is impossible while some perceive it as important. The YoHI male segment thinks that saving is security and that it is satisfying. To the $\mathrm{OHI}$ male segment, saving represents some commitment, and to a lesser extent, it also represents an investment, postponement of gratification and security. The $\mathrm{OHI}$ male segment also thinks that saving is important and should be encouraged at a young age, albeit with little emphasis on these latter beliefs.

In the female category, the YoLI segment believes that saving provides a sense of security. Some additional beliefs are that saving is a long-term investment, which requires personal responsibility that should be started at a young age. While the YoHI female segment had low representation, it perceives saving as a personal responsibility. The OLI female segment believes that saving is important and that is has a long-term orientation. On the other hand, the $\mathrm{OHI}$ female segment mostly believes that saving provides security and requires commitment. This segment holds several additional beliefs indicating that saving should be long term, encouraged at a young age and it represents postponement of immediate gratification. This segment also attaches mixed emotions towards saving denoting that it is impossible, not beneficial, while some evaluate it as exciting.

Overall, there are four significant segments based on the attitude of savers, age, gender and income, namely, the $\mathrm{OHI}$ male, $\mathrm{OHI}$ female, YoHI male and YoLI male segments. The other segments of OLI male, OLI female, YoLI female and YoHI female participants were poorly represented. 


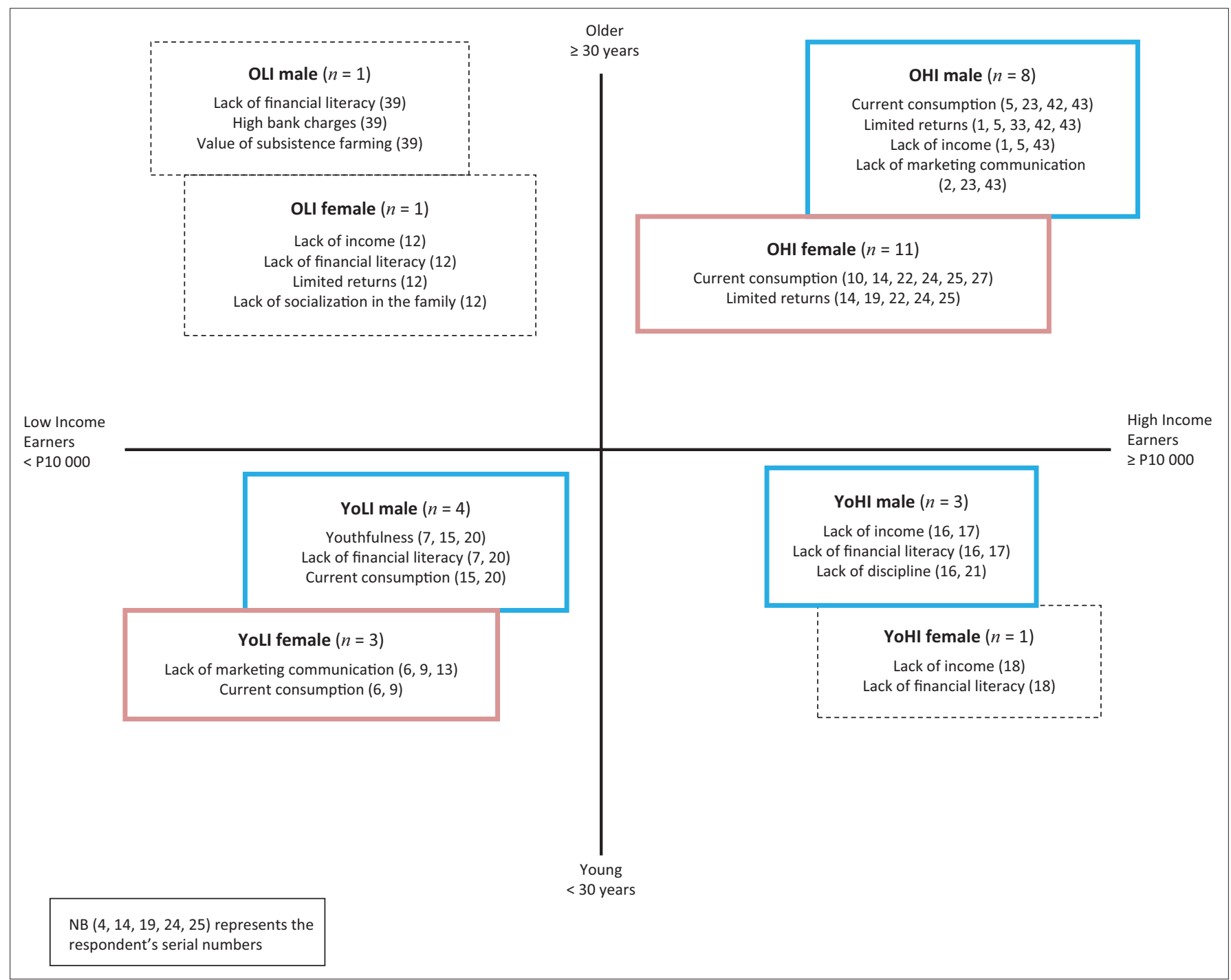

Source: Authors' own work

FIGURE 4: Perceived conditions affecting saving.

In Figure 4, eight segments are identified based on perceived conditions affecting savings. The YoLI male segment mostly perceives psychological variables such as youthfulness, current consumption and lack of financial literacy as fundamental for the poor saving culture. The YoHI male segment considers demographic and psychological variables such as lack of income and lack of financial literacy as instrumental in shaping saving behaviour. For the OLI male segment, factors that are perceived as instrumental in shaping saving behaviour include lack of financial literacy, high bank changes and social impressions about the value of subsistence farming. The OHI male segment seems to hold varied perceptions about the critical factors that influence saving. In particular, the $\mathrm{OHI}$ male segment reveals that saving is affected by a combination of factors such as lack of income, current consumption, lack of marketing communication and limited returns for saving.

In the female category, the YoLI female segment perceives marketing education and current consumption as key hindrances for saving while the OHI female segment perceives current consumption and limited returns as inhibitors of saving. For the OLI female segment, factors such as lack of income, lack of financial literacy, limited returns and lack of family training (socialisation) on saving are considered key inhibitors of saving.

All in all, five sizeable segments identified were the $\mathrm{OHI}$ male, OHI female, YoLI male, YoLI female and YoHI male segments. The other three segments of OLI male, OLI female and YoHI female were poorly represented and therefore not sizeable.

\section{Discussion and conclusions}

Overall, findings based on the analysis of a combination of the demographic and psychographic variables used in this study identified three segments for the male category that could be interpreted, that is OHI male, YoLI male and YoHI male segments for each of the four psychographic characteristics, while only two segments were identified for 
the female category, that is, $\mathrm{OHI}$ female segment (for all the respective psychographic characteristics) and YoLI female segment (for only personal values and motives).

The YoLI male segment comprises $25 \%$ of the sample of male savers. This segment represents male savers who are young and have low incomes that tend to place more emphasis on a combination of safety and security and self-fulfilment. This segment is also highly driven by social needs and holds strong beliefs in a long-term orientation of saving as an investment. The segment also perceives being young, being financially illiterate and having excessive current consumption as key impediments of saving. This segment has some traits that correspond to the financially confused segment proposed by Harrison (1994).

The YoHI male segment comprises 19\% of the sample of male savers. The segment constitutes male savers who are young, earn high incomes and consider a combination of safety and security and self-accomplishment to be more important in their daily lives. This segment is motivated by safety needs and believes that saving is a form of security. The lack of income, financial literacy and discipline dominate their perceptions concerning the barriers of saving. This segment resembles the safety players (Keller \& Siegrist 2006), cautious investors (Harrison 1994) and rational consumers (Fünfgeld \& Wang 2009).

The OHI segment is the largest, and it constitutes $50 \%$ of the sample of male savers. This segment comprises old and highincome earners. This segment has a tendency to place emphasis on a combination of the values of safety and security and sense of belonging. The segment is also highly motivated to satisfy safety and social needs through saving. They believed that saving is important and requires commitment. Lack of income, current consumption and inadequate marketing aspects of saving such as marketing communication, high bank charges, as well as poor returns were perceived to be major barriers for saving by the segment. This segment bears some similarities with financially involved adults (Ansell et al. 2007) and apathetic minimalists (Harrison 1994).

Based on the significance of the segment size, only two segments of female savers emerged. The YoLI female segment comprises $18 \%$ of the category. This segment attaches high importance to the value of a sense of belonging. The YoLI female segment is highly driven to satisfy safety needs. Saving is believed to be a form of security, which they perceive to be largely and negatively affected by the lack of marketing communication and current consumption. The segment is consistent with the safety players (Keller \& Siegrist 2006), cautious investors (Harrison 1994) and rational consumers (Fünfgeld \& Wang 2009) just as in the case of the YoHI male segment.

The second segment is the OHI female segment that represents more than two-thirds $(69 \%)$ of the sample of female savers. The most prominent value for this group is a sense of accomplishment. Safety needs are the primary motive for saving for this segment and saving is believed to be a form of security that calls for more commitment. This segment has negative emotions of saving and perceives factors such as current consumption, high debt dependency and limited returns as key barriers of saving. The segment mirrors the capital accumulators (Harrison 1994) and sophisticated late starters (Ansell et al. 2007).

Overall, it appears that the female segment is more financially cautious at a young age and financially liberal at an older age while it is the opposite for the male segment. The present study provides meaningful insight into segments of savers using a multi-dimensional approach of saving behaviour, which adds to the existing body of knowledge (Alfansi \& Sargeant 2000; Ansell et al. 2007; Keller \& Siegrist 2006). A distinct feature of this multi-dimensional approach is that it provides a more comprehensive combination of demographics aspects such as age, gender and income status and psychographic characteristics such as personal values, motives, attitudes and perceptions acting as bases of segmenting savers.

\section{Managerial implications}

Financial institutions could design products and communication strategies specifically to target these segments. For instance, in order to communicate effectively with the YoLI male segment, financial institutions need to develop extensive advertising campaigns that create awareness of various saving options that are well suited for young people with low incomes yet faced with the challenges of balancing the demands of high current consumption and having a long-term orientation. Communication strategies should also demonstrate how the various saving options will help them satisfy their need to secure the future while also ensuring that they remain fulfilled. As this segment is motivated by social needs, it is important for financial institutions to target them with saving options that have a group orientation such as a family saving plan or Motshelo (i.e. informal savings and credit cooperatives). Celebrity endorsers could also be a viable option to tackle the negative emotions they attach to saving.

While communicating with the YoLI female and YoHI male segments, financial institutions could engage in extensive personal selling efforts in order to address their lack of financial literacy. Specifically for the YoLI female segment, financial institutions could use advertising campaigns and saving options that emphasise group interaction as they value a sense of belonging and is motivated by safety needs.

The $\mathrm{OHI}$ male and female segments require more attractive returns from savings, which would make them feel that it is worth their effort. This would reinforce their positive attitudes about saving and enhance their knowledge about the various saving options that are linked to their need for 
safety. In addition, financial institutions should provide them with adequate marketing information about how to remain committed to the goal of saving in the face of increased consumption. With the OHI female segment, financial institutions could also offer saving options considered to be highly risky such as speculative stock and security bonds in order to appeal to their sense of accomplishment.

\section{Study limitations and future research avenues}

The recommendations should be considered in light of the following limitations. The present study focuses on segments of savers based on demographics and psychographics and benefits were not measured explicitly. It is worth noting that benefits sought when saving was captured implicitly as they are addressed within the conceptualisations of saving motives and beliefs. However, a more comprehensive multidimensional approach that embraces socio-cultural dimensions could be employed in the future in order to yield more interpretable segments. Considering that qualitative techniques relying on employed adults residing in the city were used in the study, the generalisation of the findings to the entire population of savers could be limited. This study provides preliminary insights intended to provoke more research that utilises multiple bases for segmenting the market of financial saving programmes. Future research could take advantage of sophisticated quantitative methods using large samples to investigate the predictive power of the variables adopted in this study across segments. There is also more representation of older employees with high incomes. Perhaps, this might imply that most savers fall in this category; nonetheless, future research could eliminate the bias by ensuring proportional representation.

\section{Acknowledgements}

We would like to thank the three blind reviewers who helped us improve the manuscript into an acceptable final output and the University of Botswana for financing the study.

\section{Competing interests}

The authors declare that they have no financial or personal relationships which may have inappropriately influenced them in writing this article.

\section{Authors' contributions}

R.M. was responsible for the methodological approach, while P.T.M. and T.M. were responsible for data collection. T.M. and R.M. were responsible for analysis and coordinating the paper write-up.

\section{References}

Aaker, J., 1997, 'Dimensions of brand personality', Journal of Marketing Research 34(3), 347-356. http://dx.doi.org/10.2307/3151897

Albert, A. \& Modigliani, F., 1963, 'The "life-cycle" hypothesis of saving: Aggregate implications and tests', American Economic Review 53(1), 55-84.
Alfansi, L. \& Sargeant, A., 2000, 'Market segmentation in the Indonesian banking sector: The relationship between demographics and desired customer benefits', International Journal of Marketing 17(2), 64-74. http://dx.doi.org/10.1108/02652320010322976

Ansell, J., Harrison, T. \& Archibald, T., 2007, 'Identifying cross-selling opportunities, using lifestyle segmentation and survival analysis', Marketing Intelligence \& Planning 25(4), 394-410. http://dx.doi.org/10.1108/02634500710754619

Burton, D., 2001, 'Savings and investment behaviour in Britain: More questions than answers', The Service Industries Journal 21(3), 130-146. http://dx.doi. org/10.1080/714005035

Carson, D., Gilmore, A., Perry, C. \& Gronhaug, K., 2001. Qualitative marketing research, Sage, London.

Central Statistics Office, 2008, 2005-6 Labour Force Report, Government Printer, Gaborone.

Coffey, J.J. \& Palm, G., 1999. 'Fixing it in the (measurement) mix', Bank Marketing 31(6), 24-29.

Devaney, S.A., Anong, S.T. \& Whirl, S.E., 2007, 'Household saving motives', The Journal of Consumer Affairs 41(1), 174-186. http://dx.doi.org/10.1111/j.1745-6606. 2006.00073.x

Doyle, P., 1987, 'Marketing and the British Chief Executive', Journal of Marketing Management 3(2), 121-132. http://dx.doi.org/10.1080/0267257X.1987.9964033

Elbadawi, I. \& Schmidt-Hebbel, K., 1998, 'Macroeconomic policies, instability, and growth across developing regions', Journal of African Economies 7, 116-168. http://dx.doi.org/10.1093/jafeco/7.suppl_2.116

Fahy, J. \& Jobber, D., 2012, Foundations of marketing, McGraw-Hill Education, New York.

Feng Lin, C., 2002, 'Segmenting customer brand preferences: Demographic or psychographic', Journal of Product \& Brand Management 11(4), 249-268. http:// psychographic', Journal of Product \& Brand
dx.doi.org/10.1108/10610420210435443

Fisher, P.J. \& Anong, S.T., 2012, 'Relationship of saving motives to saving habits', Journal of Financial Counselling and Planning 23(1), 63-79.

Foscht, T., Maloles C., III, Schloffer, J., Chia, S.-L. \& Sinha, I., 2010, 'Banking on the youth: The case for finer segmentation of the youth market', Young Consumers 11(4), 264-276. http://dx.doi.org/10.1108/17473611011093907

Friedman, M., 1957, 'The theory of the consumption function', in M. Friedman (ed.), National bureau of economic research, pp. 1-6, Princeton University Press, Princeton, NJ.

Fünfgeld, B. \& Wang, M., 2009, 'Attitudes and behaviour in everyday finance: Evidence from Switzerland', International Journal of Bank Marketing 27(2), 108-128.

Harrison, T.S., 1994, 'Mapping customer segments for personal financial services', International Journal of Bank Marketing 12(8), 17-25. http://dx.doi. org/10.1108/02652329410069010

Haruna, I., 2011, 'Determinants of saving and investments in deprived district capitals in Ghana: A case study of Nadowli in the upper west region of Ghana', Continental Journal of Social Sciences 4(1), 1-12.

Javalgi, R.G. \& Dion, P.A., 1999, 'A life cycle segmentation approach to marketing financial products and services', Service Industries Journal 19(3), 74-96. http:// dx.doi.org/10.1080/02642069900000031

Kahle, L.R., 1983, Social values and social change: Adaptation to life in America, Praeger Publishers, New York.

Keller, C. \& Siegrist, M., 2006, 'Money attitude typology and stock investment', Journal of Behavioural Finance 7(2), 88-96. http://dx.doi.org/10.1207/s15427579 jpfm0702_3

Kotler, P. \& Armstrong, G., 1999, Principles of marketing, Prentice-Hall, New York.

Kotler, P. \& Keller, K.L., 2008, Marketing management, 13th edn., Prentice-Hall, London.

Kotler, P., Keller, K.L., Ang, S.W., Leong, S.M. \& Tan, C.T., 2009, Marketing management: An Asian perspective, Prentice-Hall, Singapore.

Levesque, T., \& McDougall, G. H. (1996). Determinants of customer satisfaction in retail banking. International Journal of Bank Marketing, 14(7), 12-20. http://dx. doi.org/10.1108/02652329610151340

Loibl, C. \& Scharff, R.L., 2010, 'Examining the effect of expressing a quantitative goal on consumer savings', The Journal of Consumer Affairs 44(1), 127-154. http:// dx.doi.org/10.1111/j.1745-6606.2010.01160.x

Machauer, A. \& Morgner, S., 2001, 'Segmentation of bank customers by expected benefits and attitudes', International Journal of Bank Marketing 19(1), 6-17. $\mathrm{http}: / / \mathrm{dx}$.doi.org/10.1108/02652320110366472

McDougall, G.H. \& Levesque, T, 2000, 'Customer satisfaction with services: Putting perceived value into the equation', Journal of Services Marketing 14(4), 392-409. $\mathrm{http}: / / \mathrm{dx}$.doi.org/10.1108/08876040010340937

Meadows, M. \& Dibb, S., 1998, 'Assessing the implementation of market segmentation in retail financial services', International Journal of Service Industry Management 9(3), 266-285. http://dx.doi.org/10.1108/09564239810223565

Meier, K., Kirchler, E. \& Hubert, A.-C., 1999, 'Savings and investment decisions within private households: Spouses' dominance in decisions on various forms of investment', Journal of Economic Psychology 20(5), 499-519. http://dx.doi. org/10.1016/S0167-4870(99)00022-7

Minhas, R.S. \& Jacobs, E.M., 1996, 'Benefit segmentation by factor analysis: An improved method of targeting customers for financial services', International Journal of Bank Marketing 14(3), 3-13. http://dx.doi.org/10.1108/ 02652329610113126

Modisaatsone, N.C, 2013, 'What drives private saving in Botswana?', Journal of Economics and Behavioral Studies 5(9), 603-611. 
Muhamad, R., Melewar, T.C., \& Alwi, S.F., 2012, 'Segmentation and brand positioning for Islamic financial services', European Journal of Marketing 46(7), 900-921.

Piercy, N., Campbell, C., \& Heinrich, D., 2012, 'Suboptimal segmentation: Assessing the use of demographics in financial services advertising', Journal of Financial Services Marketing 16(3), 173-182.

Prinsloo, J.W., (2000). News and publications, viewed 28 May 2014, from South African Reserve Bank: https://www.resbank.co.za/Lists/News\%20and\%20 Publications/Attachments/2513/occ14fin.pdf

Radipotsane, M.O., 2006, 'Determinants of household saving and borrowing in Botswana', IFC Bulletin 25, 284-296.
Strandberg, C., Wahlberg, O. \& Óhman, P., 2012, 'Challenges in serving the mass affluent segment: Bank customer perceptions of service quality', Managing Service Quality: An International Journal 22(4), 359-385.

Wind, Y., 1978, 'Wind cites segmentation findings in JMR section', Marketing News $12(2), 16$.

Young, M.R., 1999, 'Market structure analysis: A foundation for developing and assessing bank strategy', International Journal of Bank Marketing, 17(1), 20-25. http://dx.doi.org/10.1108/02652329910254019

Yuh, Y. \& Hanna, S.D., 2010, 'Which households think they save?', The Journal of Consumer Affairs 44(1), 70-97. http://dx.doi.org/10.1111/j.1745-6606.2010.01158.x 


\section{Appendix 1}

TABLE 1-A1: Profile of male savers.

\begin{tabular}{|c|c|c|c|c|c|c|}
\hline Code & Age & Occupational status & Education & Income & Marital status & No. of children \\
\hline 1 & $30-39$ & Lecturer & Masters & P15 000-P19 999 & Married & 1 \\
\hline 2 & $30-39$ & Lecturer & Masters & P15 000-P19 999 & Cohabiting & 2 \\
\hline 5 & $40-49$ & Lecturer & $\mathrm{PhD}$ & P20 000-24 999 & Single & 2 \\
\hline 7 & $<30$ & Credit Controller & Degree & P5000-P9999 & Married & 1 \\
\hline 11 & $40-49$ & Assistant Manager & O-Level & P10 000-P14 999 & Married & 2 \\
\hline 15 & $<30$ & Contract Coordinator & Degree & P5000-P9999 & Single & 0 \\
\hline 16 & $<30$ & System Administrator & Degree & P15 000-P19 999 & Single & 0 \\
\hline 17 & $<30$ & Engineer & Degree & P10 000-P14 999 & Single & 0 \\
\hline 20 & $<30$ & Procurement Officer & AAT & P5000-P9999 & Married & 0 \\
\hline 21 & $<30$ & Lecturer & Masters & P15 000-P19 999 & Single & 0 \\
\hline 23 & $51-60$ & Senior Manager & $\mathrm{PhD}$ & P25 000-P29 999 & Married & 3 \\
\hline 33 & $30-39$ & Middle Manager & Tertiary certificate & P10 000-P14 999 & Married & 2 \\
\hline 36 & $40-49$ & Middle Manager & Tertiary certificate & P30 $000+$ & Divorced & 2 \\
\hline 39 & $30-39$ & Middle Manager & Tertiary certificate & P1000-P4999 & Married & 1 \\
\hline 40 & $40-49$ & Skilled Manual Worker & Tertiary certificate & - & Married & 4 \\
\hline 41 & $<30 s$ & Skilled Manual Worker & Tertiary certificate & P1000-P4999 & Single & 0 \\
\hline 42 & $50-59$ & Managing Director & MBA & P25 000-P29 999 & Married & 3 \\
\hline 43 & $30-39$ & Senior Manager & MSc & P25 000-P29 999 & Married & 2 \\
\hline
\end{tabular}

Source: Authors' own work

\section{Appendix 2}

TABLE 1-A2: Profile of female savers.

\begin{tabular}{|c|c|c|c|c|c|c|}
\hline Code & Age & Occupational status & Education & Income & Marital status & No. of children \\
\hline 3 & $50-59$ & Secretary & Diploma & P10 000-14999 & Single & 6 \\
\hline 4 & $30-39$ & Lecturer & Masters & P15 000-19 999 & Cohabitating & 1 \\
\hline 6 & $<30$ & Assistant Account Manager & Diploma & P5000-P9999 & Single & 1 \\
\hline 9 & $<30$ & Assistant Financial Accountant & Degree & P5000-P9999 & Single & 3 \\
\hline 10 & $30-39$ & Senior Manager & Diploma & P25 000-P29 999 & Married & 2 \\
\hline 12 & $30-39$ & Junior Officer & Diploma & P5000-P9999 & Married & 2 \\
\hline 13 & $<30$ & Management Officer & AAT & P5000-P9999 & Single & 1 \\
\hline 14 & $30-39$ & Loan Manager & Diploma & P10 000-14999 & Married & 3 \\
\hline 18 & $<30$ & Principal Administrator & Degree & P10 000-P14 999 & Single & 1 \\
\hline 19 & $30-39$ & Principal Revenue Officer & Degree & P15 000-P19 999 & Single & 1 \\
\hline 22 & $40-49$ & Lecturer & Masters & P15 000-P19 999 & Single & 1 \\
\hline 24 & $30-39$ & Lecturer & Masters & P15 000-P19 999 & Single & 0 \\
\hline 25 & $40-49$ & Lecturer & $\mathrm{PhD}$ & P30 000 or more & Divorced & 1 \\
\hline 26 & $40-49$ & Senior Manager & - & P30 000 or more & Single & 1 \\
\hline 27 & $50-59$ & Senior Manager & Diploma & P5000-P9999 & Married & 4 \\
\hline
\end{tabular}

Source: Authors' own work 